\title{
Reinforcement effect and mechanism of carbon fibers to mechanical and electrically conductive properties of cement-based materials
}

\author{
Baoguo Han ${ }^{1, *}$, Liqing Zhang ${ }^{1}$, Chenyu Zhang ${ }^{1}$, Yunyang Wang ${ }^{1}, \mathrm{Xun} \mathrm{Yu}^{3,4}$, Jinping Ou ${ }^{1,2}$ \\ ${ }^{1}$ School of Civil Engineering, Dalian University of Technology, Dalian, 116024 China \\ ${ }^{2}$ School of Civil Engineering, Harbin Institute of Technology, Harbin, 150090 China \\ ${ }^{3}$ Department of Mechanical \& Energy Engineering, University of North Texas, Denton, TX 76203 \\ USA \\ ${ }^{4}$ School of Machinery and Automation, Wuhan University of Science and Technology, Wuhan, \\ 430081 China \\ *Corresponding author: hithanbaoguo@163.com, hanbaoguo@dlut.edu.cn
}

\begin{abstract}
In this paper, carbon fibers with hydrophilic surface modification were added into cement mortar through ultrasonic treatment. The mechanical and electrical properties of carbon fiber filled cement mortar were tested to examine the reinforcing effect of carbon fiber. In order to understand the underlying modification mechanisms of carbon fibers to cement mortar at micro scale and in theory, scanning electron microscope (SEM) observation and theoretical calculations were carried out. Test results indicate that the adding of carbon fibers into cement mortar enhances the mechanical strength (especially compressive strength), and decreases the electrical resistivity of carbon fiber filled cement mortar. SEM results show that the enhancement of the properties of carbon fiber filled cement mortar owes to fiber ability of restraining the growth of microcracks and absorbing energy by overcoming its pulling out. The enhancing mechanism of carbon fibers on the properties of cement mortar analyzed by the calculated fiber numbers per unit volume, average center distance between two carbon fibers and the critical pull-out length well matches the experimental results.
\end{abstract}


Keywords: carbon fiber; cement mortar; mechanical properties; electrical conduction; reinforcement mechanism

\section{Introduction}

As a new generation of reinforcing fiber of cement-based composite, carbon fibers have many well-known properties such as low density, low heat transfer coefficient and expansion coefficient, high tensile strength, corrosion resistance, good toughness and durability, good chemical stability and heat conduction performance [1], [2], [3], [4], [5] [6], [7], [8] and [9]. In addition, carbon fibers with different volume fractions not only can obviously improve the mechanical properties, enhance the capacity of deformation and control the growth of cracks, but also expand the application scope of cement-based materials by giving some functional or intelligent features to carbon fiber reinforced cement composites (CFRC) [3], [10] and [11].

The literature has a considerable amount of work on mechanical properties of CFRC. Toutanji et al. [6] studied that the addition of $1 \%, 2 \%$ and $3 \%$ vol. of carbon fiber to cement matrix results in an increase in the flexural strength of $72 \%, 95 \%$ and $138 \%$, respectively. Park et al. [12] mixed the carbon fiber loading of 1 vol. $\%, 2$ vol. $\%$ and 3 vol. \% with cement mortar. Test results showed that $14 \mathrm{~d}$ tensile strengths of cement mortar with 1 vol.\%, 2 vol.\% and 3 vol.\% carbon fiber increased by $103 \%, 172 \%$ and $255 \%$ than that of ordinary cement mortar, respectively. Xu et al. [13] observed that the tensile strength of cement paste was increased by $56 \%$ and the modulus and ductility were increased by $39 \%$ by using silane-treated carbon fibers and silane-treated silica fume, relative to the values for cement paste with as-received carbon fibers and as-received silica fume. In addition, the toughening effect of carbon fiber on 
cement-based material matrix and constitutive relation under cyclic loadings were studied by Deng et al. [14].

Effect of carbon fiber on electrical property of CFRC has also been studied. It is found that the conductive mechanism of CFRC was tunnel conductive effect [15], [16] and [17]. Chen et al. [18] studied the influence of carbon fiber volume, size, cement-based matrix, relative humidity and curing age on the characteristic of the system and investigated the percolation phenomenon by using scanning electron microscope (SEM). Manuela et al. [19]studied the effect of the carbon fiber length and volume fraction on the resistivity of CFRC. Test results indicated that the resistivity of CFRC decreased as the length of carbon fiber increased. The results of Chen et al. [20] showed that the change of volume resistivity was linked with the closure and development of internal cracks and the interface contact state between carbon fiber and cement-based composites. In addition, Chen et al. [21] examined the effect of different carbon fiber contents on pressure sensibility of CFRC and built up the model of relationship between resistance and strength. Besides, it is found that the health monitoring of civil engineering structure, stress/strain sensor, self-sensing and self-diagnosis could be achieved by smart CFRC [22], [23], [24], [25] and [26].

Most previous work examine the effects of carbon fiber on cement-based materials, but it is found that compressive strength is not improved obviously and even is decreased. However, in this paper, we use fiber hydrophilic surface modification and ultrasonic treatment methods to effectively disperse carbon fibers in cement mortar, and investigate the effects of carbon fiber on the properties of cement mortar with 84 carbon fiber filled cement mortar specimens. Meanwhile, the results calculated with theoretical analysis have been compared to the experimental results. As a result, the mechanical 
and electrical properties have been improved, especially the compressive strength is enhanced obviously.

\section{Experimental}

\subsection{Materials}

In this research, $3 \mathrm{~mm}$ and $6 \mathrm{~mm}$ PAN-based carbon fibers with hydrophilic surface modification, made in Jilin Chemical Industry Co. LTD, are used. The performance parameters of carbon fibers are shown in Table 1. P.O 42.5R Portland cement (Dalian Onoda Cement Co. Ltd., China) was applied as binder materials. Standard sand (Xiamen Ai Si Ou Standard Sand Co. Ltd., China) was used as fine aggregate. The water reducer is $3310 \mathrm{E}$ polycarboxylate superplasticizer provided by Dalian Xi Ka whose solid content is $45 \%$ and can reduce water to an extent of $30 \%$. In addition, densities of raw materials are shown in Table 2. Stainless steel gauzes with opening of $50 \mathrm{~mm} \times 50 \mathrm{~mm}$ were used as electrodes whose length and width are 10 and 6 whole grids, respectively [27].

Table 1 Physical properties of polypylene carbon fiber

\begin{tabular}{cccc}
\hline Diagram $(\mu \mathrm{m})$ & Tensile strength $(\mathrm{MPa})$ & Tensile modulus $(\mathrm{GPa})$ & Density $\left(\mathrm{kg} \cdot \mathrm{m}^{-3}\right)$ \\
\hline 7 & 3450 & 230 & 1800 \\
\hline
\end{tabular}

Table 2 Densities of raw materials

\begin{tabular}{ccccc}
\hline Raw materials & Cement & Sand & Water & Water reducer \\
\hline Density $\left(\mathrm{kg} \cdot \mathrm{m}^{-3}\right)$ & 3100 & 2650 & 1000 & 1100 \\
\hline
\end{tabular}

\subsection{Sample preparation}


Table 3 Mix proportion

\begin{tabular}{cccccc}
\hline NO. & $\begin{array}{c}\text { Cement } \\
\left(\mathrm{kg} / \mathrm{m}^{3}\right)\end{array}$ & $\begin{array}{c}\text { Water } \\
\left(\mathrm{kg} / \mathrm{m}^{3}\right)\end{array}$ & $\begin{array}{c}\text { Sand } \\
\left(\mathrm{kg} / \mathrm{m}^{3}\right)\end{array}$ & $\begin{array}{c}\text { Water reducer } \\
\left(\mathrm{kg} / \mathrm{m}^{3}\right)\end{array}$ & $\begin{array}{c}\text { Carbon fiber } \\
\left(\mathrm{kg} \cdot \mathrm{m}^{3}\right)\end{array}$ \\
\hline 0 & 545 & 207.1 & 1653 & $0(0 \%)$ & $0(0 \%)$ \\
1 & 545 & 207.1 & 1653 & $0.5450(0.1 \%)$ & $1.090(0.2 \%)$ \\
2 & 545 & 207.1 & 1653 & $0.8175(0.15 \%)$ & $2.725(0.5 \%)$ \\
3 & 545 & 207.1 & 1653 & $2.3980(0.44 \%)$ & $4.360(0.8 \%)$ \\
4 & 545 & 207.1 & 1653 & $2.7250(0.50 \%)$ & $5.995(1.1 \%)$ \\
5 & 545 & 207.1 & 1653 & $3.2700(0.60 \%)$ & $8.175(1.5 \%)$ \\
6 & 545 & 207.1 & 1653 & $3.8150(0.70 \%)$ & $10.900(2.0 \%)$ \\
\hline
\end{tabular}

A total of 13 cement mortar mixes containing five components, namely cement, water, sand, water reducer and carbon fibers, were prepared. The water/cement ratio is fixed at 0.38. Carbon fiber loadings of $0,0.2,0.5,0.8,1.1,1.5$ and 2.0 percent per mass of cement were used to fabricate the carbon fiber filled cement mortar. The dosage of water reducer increases with the increase of the dosage of carbon fibers to ensure necessary fluidity for specimen molding. The mix proportions of carbon fiber filled cement mortar show in Table 3. There were 6 specimens for each mix proportion. Three of them (marked as Sample-1-3d, Sample-2-3d, and Samples-3-3d) are for the performance test at 3d, and others (marked as Sample-1-28d, Sample-2-28d, and Samples-3-28d) are for the performance test at 28d. As presented in Fig.1, the detailed manufacture process of carbon fiber filled cement mortar is as following:

(1) Mix the water reducing agent and water in the beaker with vibrating.

(2) Add carbon fibers into the water reducing agent/water solution and then put in ultrasonicator (Branson 2510 E-DTH, $100 \mathrm{~W} 42 \mathrm{KHz}$, Bransonic Ultrasonics Corporation, USA) for half an hour to get uniform suspension. 
(3) Put the suspension into sand mixer provided by Chinese Yu Hua Instrument Ltd, and then stir at low speed for 60s and pour the cement into the suspension slowly and evenly during this 60s, finally agitate the cement past at fast speed for 30 s.

(4) Add the sand into sand mixer during the first 60 s at low speed and then agitate it at high speed for 30s. After that, agitate for another 90 s.

(5) Put the uniform cement mortar into the oiled mould $(40 \mathrm{~mm} \times 40 \mathrm{~mm} \times 160 \mathrm{~mm})$ and vibrate for $20 \mathrm{~s}$.

(6) Embed two stainless-steel-wire-electrodes at both position $10 \mathrm{~mm}$ far away from the sides (as shown in Fig.2) and vibrate for another 5s.

(7) Demould specimens after curing the temperature humidity chamber $\left(20.0^{\circ} \mathrm{C}\right.$ and $95 \%$ relative humidity) for 24 hours.

(8) Cure the specimens in water at $20 \pm 2^{\circ} \mathrm{C}$ until test flexural and compressive strengths at $3 \mathrm{~d}$ and $28 \mathrm{~d}$.

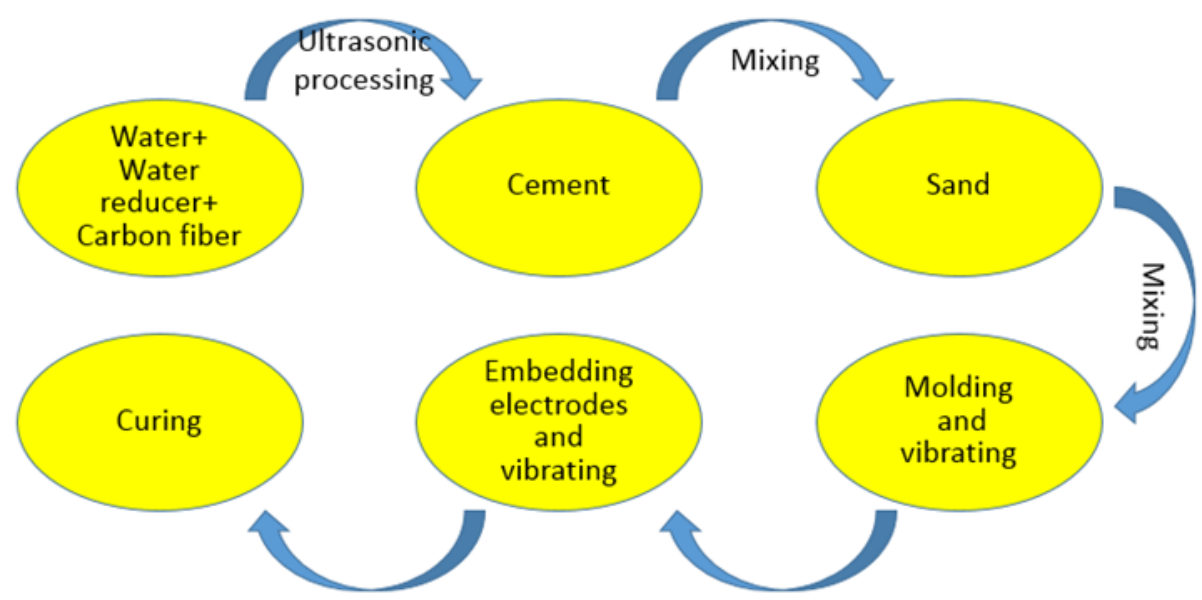

Fig.1 Specimen preparation process 


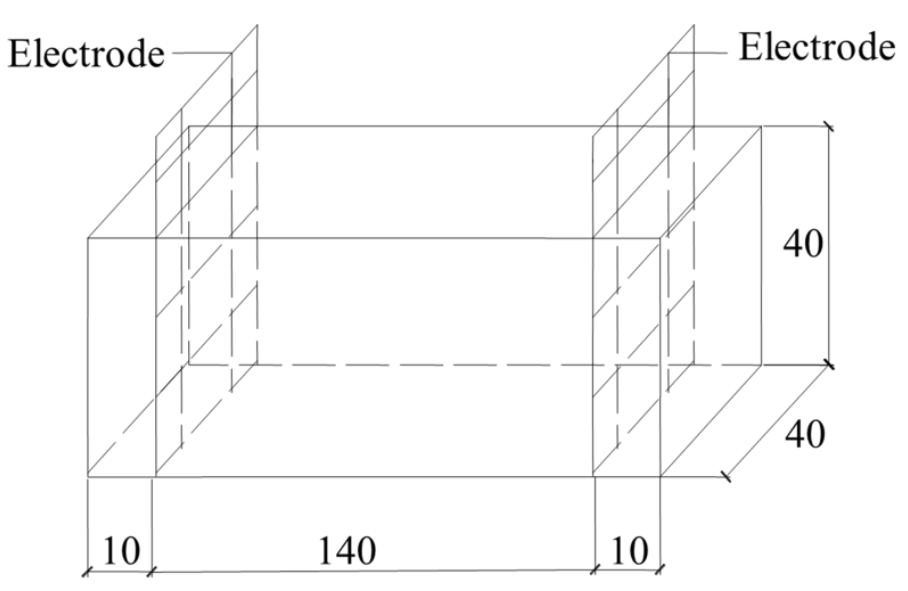

Fig.2 Dimension of the specimen and electrode arrangement

\subsection{Measurement}

The flexural strength was measured by using the mortar folding meter DKZ-5000 provided by Wuxi Jianyi Instrument \& Machinery Co., Ltd. The compressive strength was measured by universal testing machine WDW-200E (Jinan Times Shijin Test Machine Co., Ltd). The compressive strengths of specimens were tested in displacement-controlled mode with a displacement rate of $1.2 \mathrm{~mm} / \mathrm{min}$. Resistance of the specimens without loading were tested by a two-electrode method by using a handheld LCR meter (U1733C, Agilent Technologies, Inc., USA) with $0.2 \%$ of measuring accuracy. Field Emission Scanning Electron Microscope (Nova Nano SEM 450, American FEI Ltd) was used to observe the morphology of the carbon fiber filled cement mortar.

\section{Experimental results and discussions}

\subsection{Flexural strength of carbon fiber filled cement mortar}

Figs.3-5 show the relationships between $3 \mathrm{~d}$ flexural strength and carbon fiber content. Table 4 shows the increase rate of $3 \mathrm{~d}$ flexural strength of carbon fiber filled cement mortar specimens. 


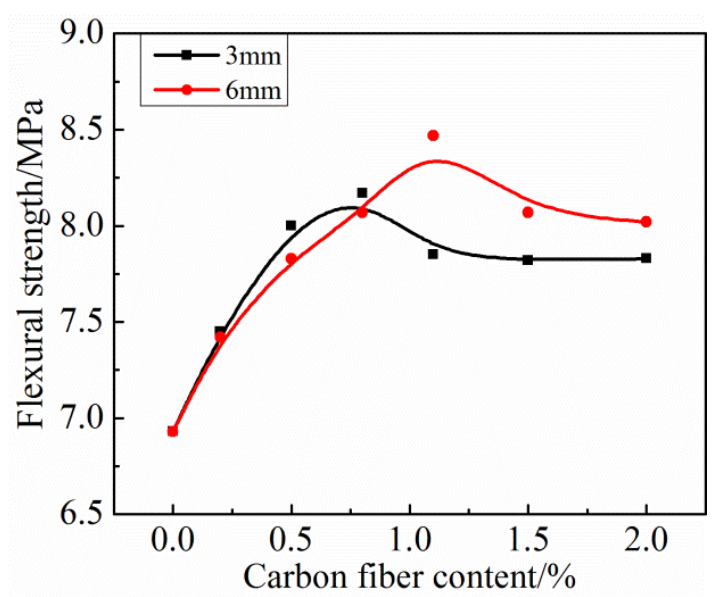

Fig.3 3d flexural strength of carbon filled cement mortar

Table 4 The increase rate of $3 \mathrm{~d}$ flexural strength of carbon fiber filled cement mortar

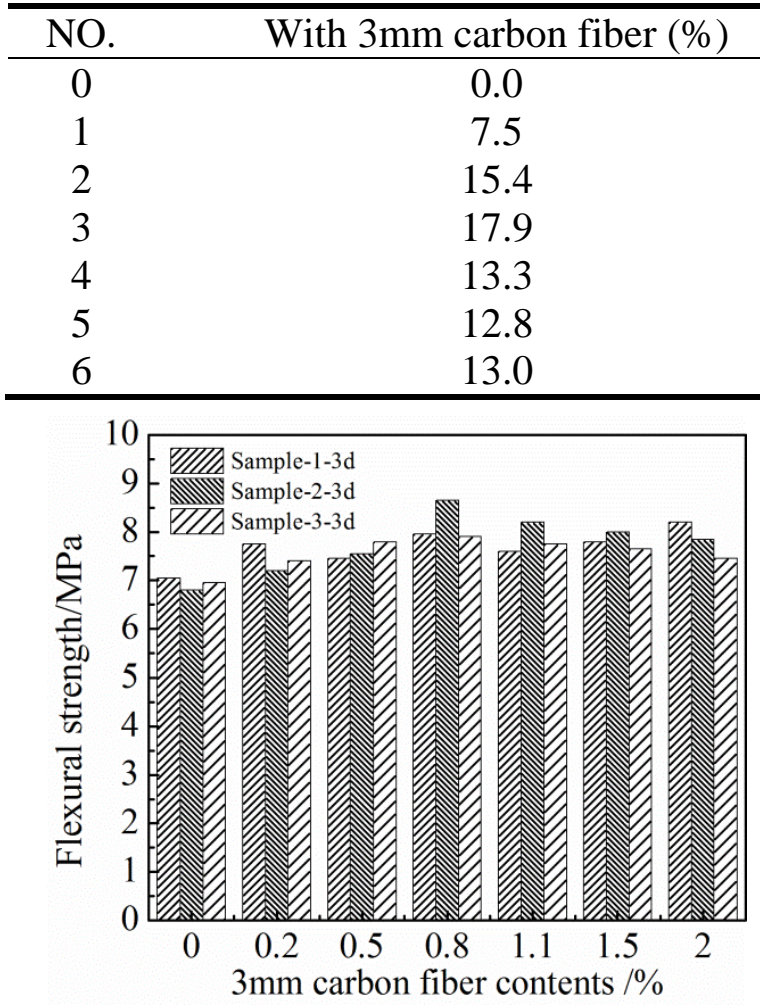

Fig.4 Flexural strengths of $3 \mathrm{~mm}$ carbon
With $6 \mathrm{~mm}$ carbon fiber $(\%)$

0.0

7.1

13.0

16.5

22.2

16.5

15.0

fiber filled cement mortar at $3 \mathrm{~d}$

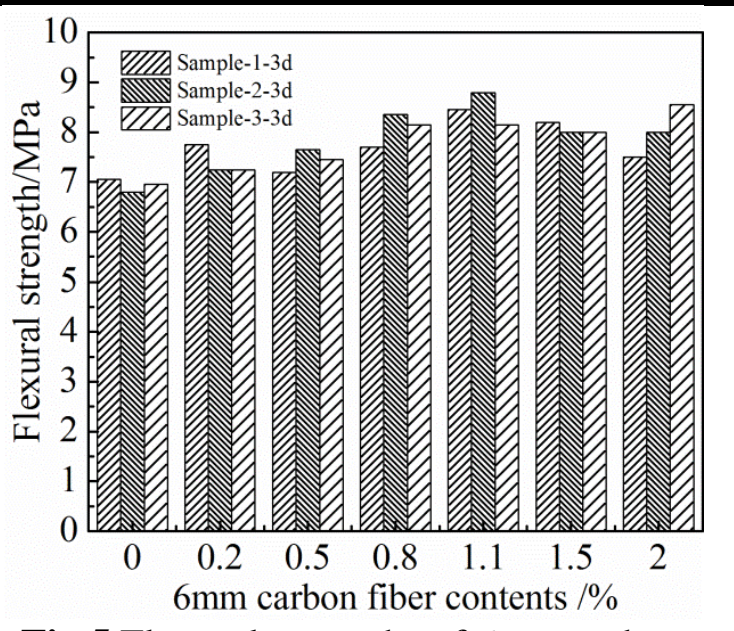

Fig.5 Flexural strengths of $6 \mathrm{~mm}$ carbon

fiber filled cement mortar at $3 \mathrm{~d}$

Fig. 3 and Table 4 indicate that the flexural strengths of carbon fiber filled cement mortar firstly increase and then decrease as the carbon fiber content increases. The $3 \mathrm{~d}$ 
flexural strengths of $3 \mathrm{~mm}$ carbon fiber filled cement mortar reach the maximum when the carbon fiber content is $0.8 \%$. And the maximum $3 \mathrm{~d}$ flexural strength was $8.2 \mathrm{MPa}$ and increases by $17.9 \%$. When the fiber content is over $0.8 \%$, the flexural strengths of carbon fiber filled cement mortar decrease with increasing of carbon fiber content. However, the $3 \mathrm{~d}$ flexural strengths still maintain in the range from $7.9 \mathrm{MPa}$ to $7.8 \mathrm{MPa}$ which are higher than that of plain specimen without fiber. In addition, the optimal content for $3 \mathrm{~d}$ flexural strength of $6 \mathrm{~mm}$ carbon fiber filled cement mortar is $1.1 \%$. The maximum $3 \mathrm{~d}$ flexural strength was $8.5 \mathrm{MPa}$ enhanced by $22.2 \%$ compared with plain specimen without fiber. It should be noted that the flexural strengths of $6 \mathrm{~mm}$ carbon fiber filled cement mortar are all higher than that of plain specimen without fiber.

When the carbon fiber content is less than $0.8 \%$, the enhancing effect of $3 \mathrm{~mm}$ carbon fiber is more obvious than that of $6 \mathrm{~mm}$ fiber at the same content. However, when the carbon fiber content is more than $0.8 \%$, it is opposite.

Figs. 4 and 5 show that the 3 specimens in each group have similar flexural strength and the dispersion degrees are within $10 \%$. The results indicate that the dispersion effect of carbon fibers in the cement mortar is good enough for fabricating carbon fibers filled cement mortars with stable properties.

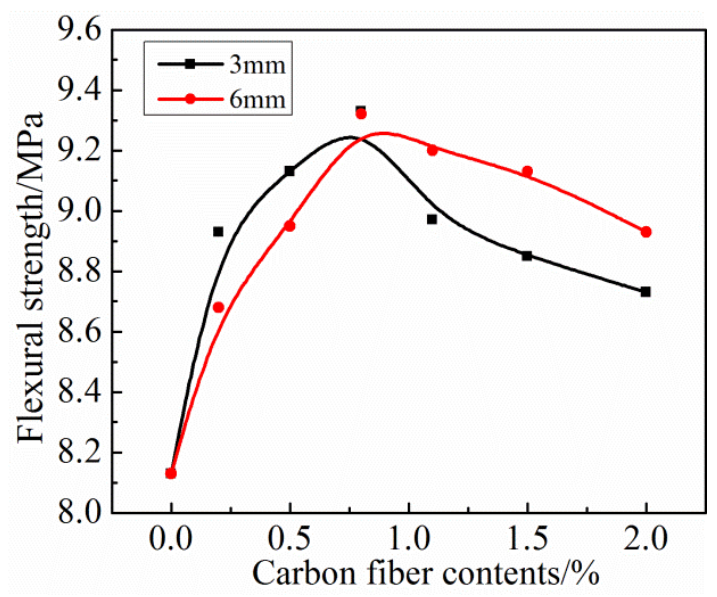


Fig.6 28d flexural strength of carbon fiber filled cement mortar

Table 5 The increase rate of flexural strength of carbon fiber filled cement mortar at

$28 d$

\begin{tabular}{ccc}
\hline NO. & With 3mm carbon fiber $(\%)$ & With $6 \mathrm{~mm}$ carbon fiber $(\%)$ \\
\hline 0 & 0.0 & 0.0 \\
1 & 9.8 & 6.8 \\
2 & 11.1 & 10.1 \\
3 & 14.8 & 14.6 \\
4 & 10.3 & 11.9 \\
5 & 8.9 & 12.3 \\
6 & 7.4 & 9.8 \\
\hline
\end{tabular}

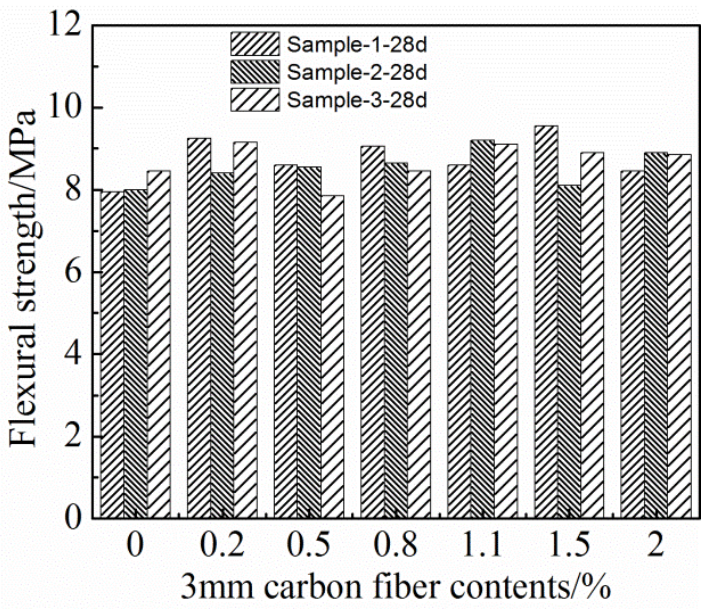

Fig.7 Flexural strengths of $3 \mathrm{~mm}$ carbon

fiber filled cement mortar at $28 \mathrm{~d}$

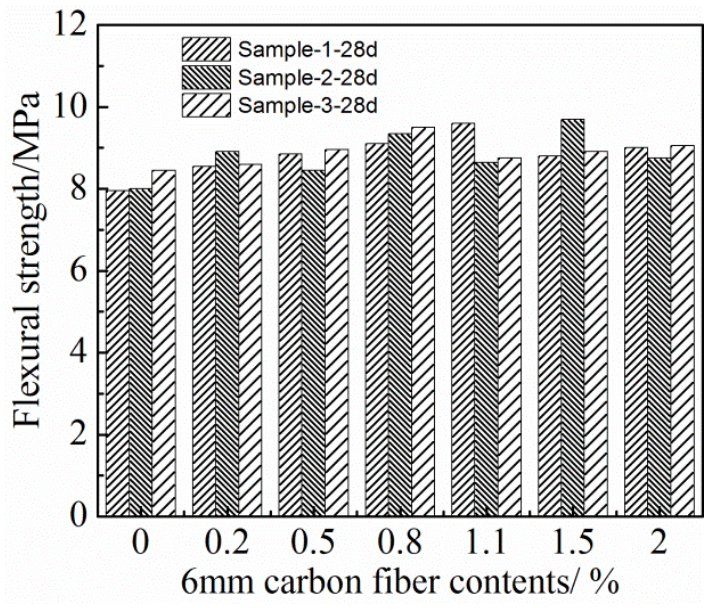

Fig.8 Flexural strengths of $6 \mathrm{~mm}$ carbon

fiber filled cement mortar at $28 \mathrm{~d}$

Figs.6-8 show the relationships between $28 \mathrm{~d}$ flexural strength and carbon fiber content. Table 5 shows the increase rate of flexural strength of carbon fiber filled cement mortar at 28d. Fig.6 indicates that the $28 \mathrm{~d}$ flexural strengths of carbon fiber filled cement mortar firstly increase and then decrease by increasing of carbon fiber content.

When the content of $3 \mathrm{~mm}$ carbon fiber is $0.8 \%$, the $28 \mathrm{~d}$ flexural strength reaches maximum value and increases by $14.8 \%$ compared with plain specimen without fiber. 
However, the flexural strength of $3 \mathrm{~mm}$ carbon fiber filled cement mortar decreases with the carbon fiber content increase when the fiber content is over $0.8 \%$. The $28 \mathrm{~d}$ strengths still maintain in the range from $8.97 \mathrm{MPa}$ to $8.73 \mathrm{MPa}$, which are higher than that of plain specimen without fiber. In addition, the optimal content for $28 \mathrm{~d}$ flexural strength of $6 \mathrm{~mm}$ carbon fiber filled cement mortar is also $0.8 \%$. And the maximum flexural strength enhances by $14.6 \%$ relative to plain specimen without fiber. It also can find that the flexural strengths of $6 \mathrm{~mm}$ carbon fiber filled cement mortar are all higher than that of plain specimen without fiber.

When the carbon fiber content is less than $0.8 \%$, the enhancing effect of $3 \mathrm{~mm}$ carbon fiber is more obvious than that of $6 \mathrm{~mm}$ carbon fiber at the same fiber content. However, when the carbon fiber content is more than $0.8 \%$, it is opposite.

As shown in Figs.7 and 8, the dispersion degrees of 3 specimens in each group are small (within 10\%) which indicate that the carbon fibers are uniformly distributed in the cement mortar.

\subsection{Compressive strength of carbon fiber filled cement mortar}

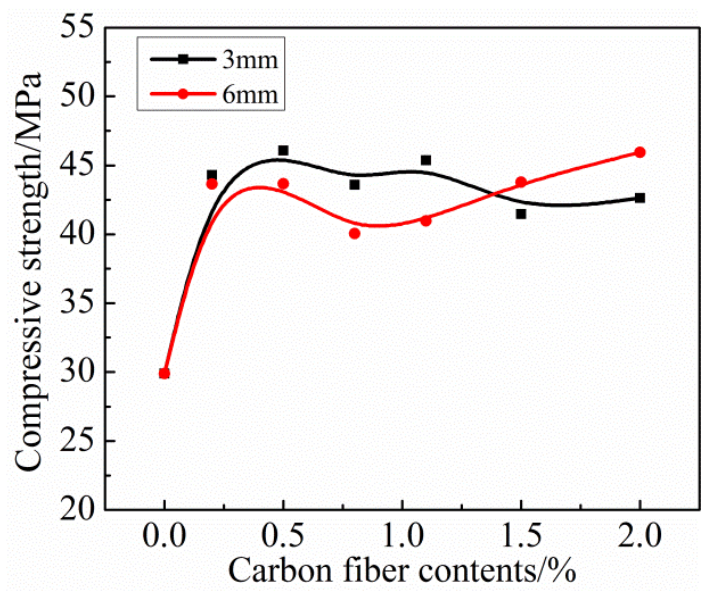

Fig.9 Compressive strength of carbon fiber filled cement mortar at $3 \mathrm{~d}$ 
Table 6 The increase rate of compressive strength of carbon fiber filled cement mortar at $3 \mathrm{~d}$

\begin{tabular}{ccc}
\hline NO. & With 3mm carbon fiber $(\%)$ & With $6 \mathrm{~mm}$ carbon fiber $(\%)$ \\
\hline 0 & 0.0 & 0.0 \\
1 & 48.2 & 46.0 \\
2 & 54.1 & 46.0 \\
3 & 45.8 & 33.9 \\
4 & 51.7 & 37.1 \\
5 & 38.7 & 46.4 \\
6 & 42.6 & 53.6 \\
\hline
\end{tabular}

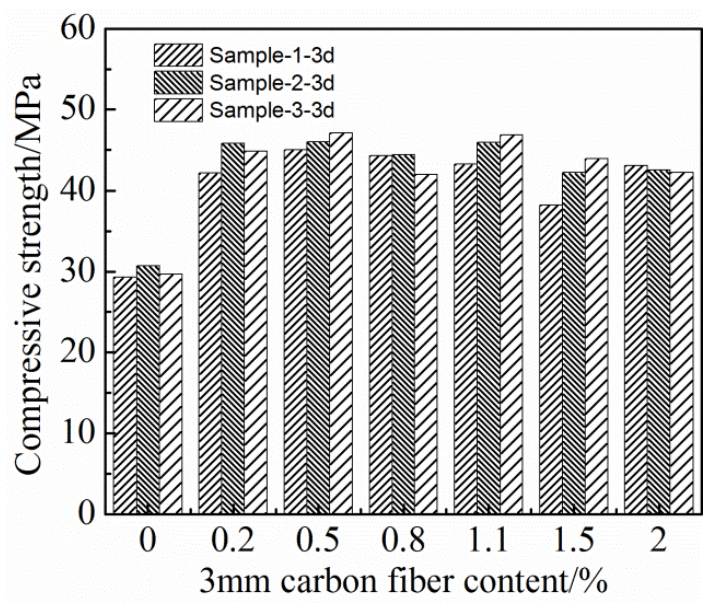

Fig.10 Compressive strengths of $3 \mathrm{~mm}$

carbon fiber filled cement mortar at $3 \mathrm{~d}$

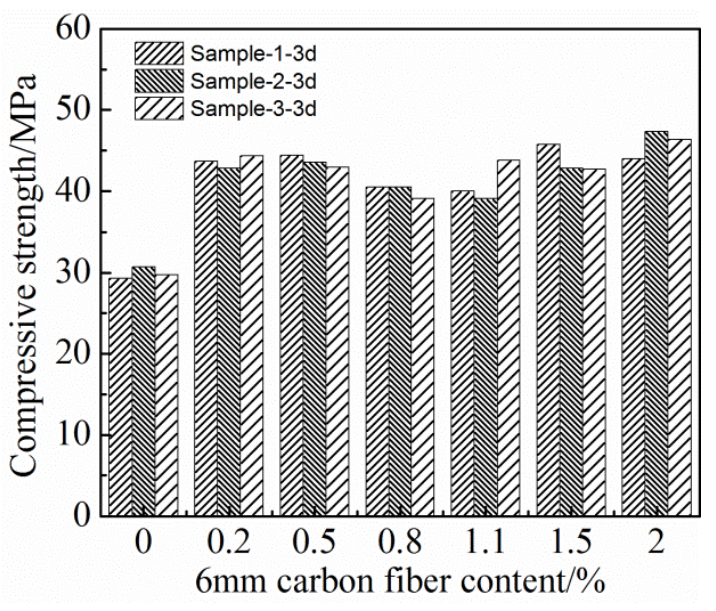

Fig.11 Compressive strengths of $6 \mathrm{~mm}$

carbon fiber filled cement mortar at $3 \mathrm{~d}$

Figs.9-11 are the curves of relationships between $3 \mathrm{~d}$ compressive strength and carbon fiber content for both $3 \mathrm{~mm}$ and $6 \mathrm{~mm}$ carbon fiber. Table 6 is the increase rate of $3 \mathrm{~d}$ compressive strength of carbon fiber filled cement mortar for both $3 \mathrm{~mm}$ and $6 \mathrm{~mm}$ carbon fiber.

Fig.9 shows that the $3 \mathrm{~d}$ compressive strengths of carbon fiber filled cement mortar firstly increase in a sharp gradient, and then the increase of compressive strengths is slight even decreased when the content is over $0.5 \%$. 
For the specimen with $3 \mathrm{~mm}$ carbon fibers, the maximum $3 \mathrm{~d}$ compressive strength is $46.08 \mathrm{MPa}$ and increases by $54.1 \%$ when the content of carbon fiber is $0.5 \%$. When the fiber content overpasses $0.5 \%$, the trend of the enhancement of compressive strength of carbon fiber filled cement mortar reduces gradually. However, the compressive strengths keep in the range from $43.58 \mathrm{MPa}$ to $41.46 \mathrm{MPa}$, which are still much higher than that of plain specimen without fiber. Besides, when the carbon fiber content is $0.2 \%$, the $3 \mathrm{~d}$ compressive strengths of $6 \mathrm{~mm}$ carbon fiber filled cement mortar reach the first peak value. However, the compressive strengths reduce gradually when the fiber content is over $0.2 \%$ but less than $0.8 \%$. The $3 \mathrm{~d}$ compressive strengths of $6 \mathrm{~mm}$ carbon fiber filled cement mortar reach the maximum when the content is $2.0 \%$. In addition, the maximum compressive strength is $45.93 \mathrm{MPa}$, which increases by $53.6 \%$. In general, the $3 \mathrm{~mm}$ carbon fiber has better enhancing effect on compressive strength of cement mortar at $3 \mathrm{~d}$ when the content is less than $1.1 \%$.

As shown in Figs.10 and 11, the 3 specimens in each group have similar compressive strength and the dispersion degrees are within $10 \%$, which shows that the dispersion effect of carbon fibers in the cement mortar is good enough for fabricating carbon fibers filled cement mortars with stable properties.

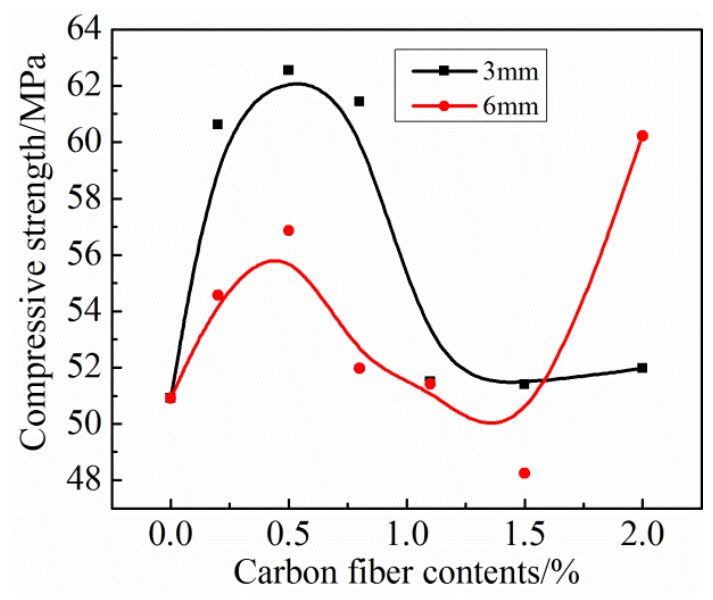


Fig.12 Compressive strength of carbon fiber filled cement mortar at 28d

Table 7 The increase rate of compressive strength of carbon fiber filled cement mortar at $28 \mathrm{~d}$

\begin{tabular}{ccc}
\hline NO. & With 3mm carbon fiber $(\%)$ & With $6 \mathrm{~mm}$ carbon fiber $(\%)$ \\
\hline 0 & 0.0 & 0.0 \\
1 & 19.0 & 7.1 \\
2 & 22.8 & 11.7 \\
3 & 20.6 & 2.1 \\
4 & 1.1 & 1.0 \\
5 & 0.9 & -5.2 \\
6 & 2.1 & 18.3 \\
\hline
\end{tabular}

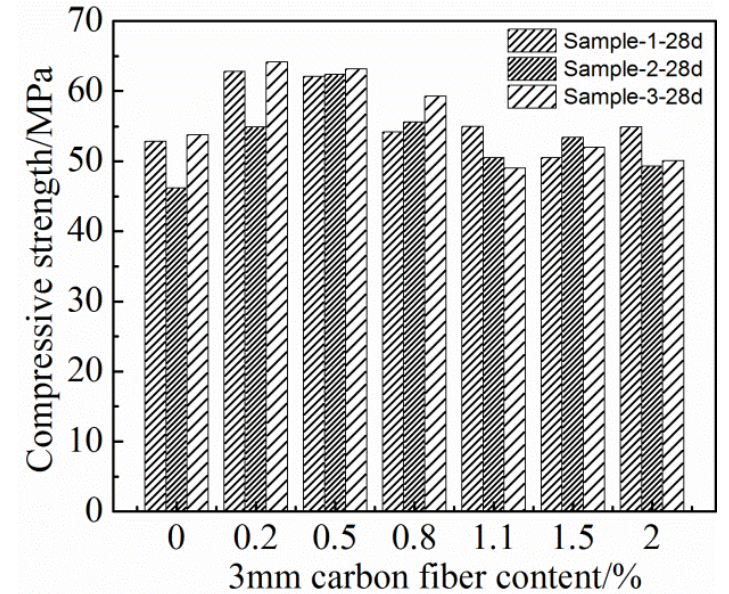

Fig.13 Compressive strengths of $3 \mathrm{~mm}$

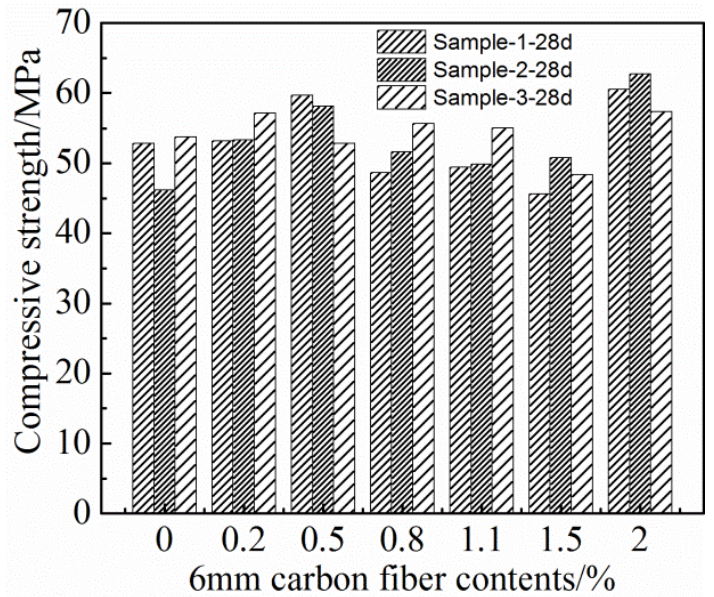

Fig.14 Compressive strengths of $6 \mathrm{~mm}$

carbon fiber filled cement mortar at $28 \mathrm{~d}$

carbon fiber filled cement mortar at $28 \mathrm{~d}$

Fig.12 shows the $28 \mathrm{~d}$ compressive strengths for $3 \mathrm{~mm}$ carbon fiber filled cement mortar and $6 \mathrm{~mm}$ carbon fiber filled cement mortar. Table 7 is the increase rate of $28 \mathrm{~d}$ compressive strength of cement mortar filled with $3 \mathrm{~mm}$ and $6 \mathrm{~mm}$ carbon fiber.

Fig. 12 indicates that the $28 \mathrm{~d}$ compressive strengths of $3 \mathrm{~mm}$ carbon fiber filled cement mortar firstly increase, then decrease and eventually begin to flatten. However, for $6 \mathrm{~mm}$ carbon fiber filled cement mortar, the $28 \mathrm{~d}$ compressive strengths eventually increase instead of flattening. 
When the $3 \mathrm{~mm}$ fiber content is $0.5 \%$, the $28 \mathrm{~d}$ compressive strengths reach the maximum value $(62.55 \mathrm{MPa})$ and increase by $22.8 \%$. When the fiber content overpasses $0.5 \%$, the trend of enhancement reduces gradually. However, the $28 \mathrm{~d}$ compressive strengths are still higher than that of plain specimen without fiber. In addition, when the $6 \mathrm{~mm}$ carbon fiber content is $0.5 \%$, the $28 \mathrm{~d}$ compressive strengths reach the first peak value, which is $56.87 \mathrm{MPa}$ and enhances by $11.7 \%$. When the carbon fiber content is over $0.5 \%$, the trend of enhancement reduces gradually. However, the $28 \mathrm{~d}$ compressive strengths of $6 \mathrm{~mm}$ carbon fiber filled cement mortar begin increasing as the fiber content overpasses $1.5 \%$. When the $6 \mathrm{~mm}$ carbon fiber content is $2.0 \%$, the $28 \mathrm{~d}$ compressive strengths can even reach $60.22 \mathrm{MPa}$, which increases by $18.3 \%$. In general, the $3 \mathrm{~mm}$ carbon fiber filled cement mortar shows much better compressive strength than that of $6 \mathrm{~mm}$ fiber filled cement mortar when the carbon fiber content is less than $1.5 \%$.

It also can be seen in Figs. 13 and 14 that the 3 specimens in each group have similar compressive strength and the dispersion degrees are within $10 \%$. The results show that the carbon fibers are uniformly distributed in the cement mortar which can be used to research stable properties.

\subsection{Electrical resistivity of carbon fiber filled cement mortar}

Figs. 15 and 16 are the electrical resistivity of $3 \mathrm{~mm}$ and $6 \mathrm{~mm}$ carbon fiber filled cement mortar. Table 8 is the electrical resistivity decrease rate of carbon fiber filled cement mortar specimens at $3 \mathrm{~d}$ and $28 \mathrm{~d}$. 


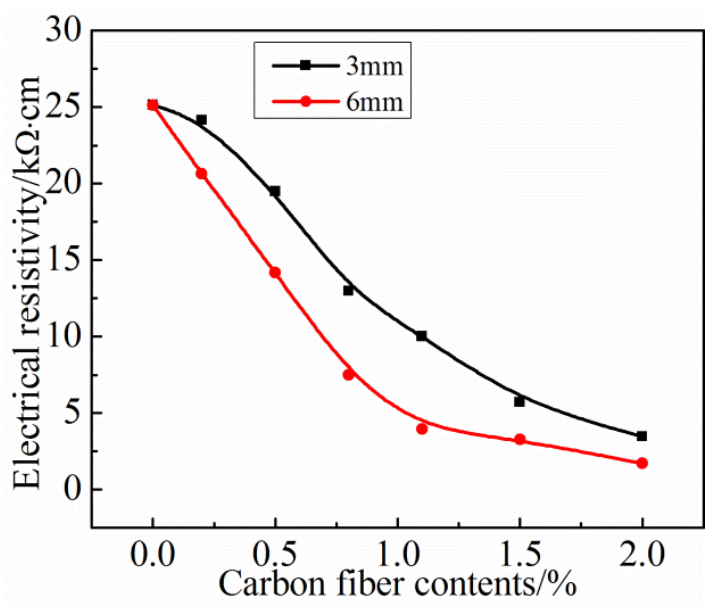

Fig.15 The electrical resistivity of

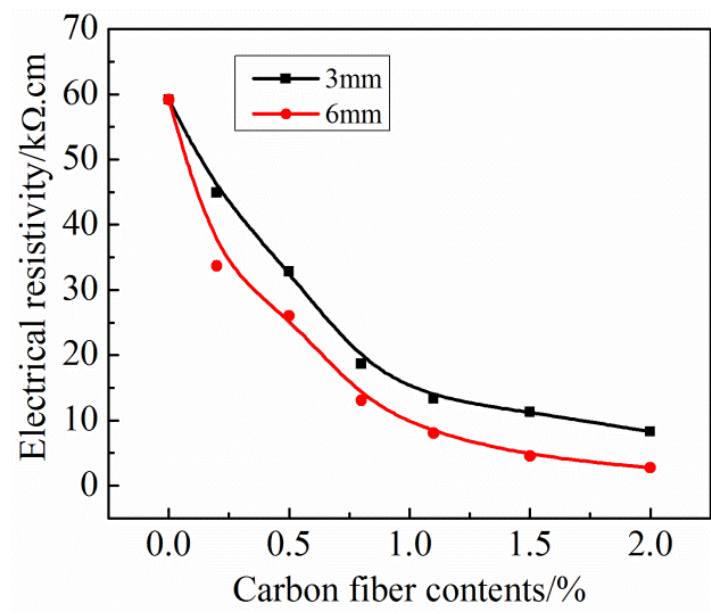

Fig.16 The electrical resistivity of

$3 \mathrm{~mm}$ and $6 \mathrm{~mm}$ carbon fiber filled cement $3 \mathrm{~mm}$ and $6 \mathrm{~mm}$ carbon fiber filled cement mortar at $3 \mathrm{~d}$ mortar at $28 \mathrm{~d}$

Table 8 The decrease rate in electrical resistivity of carbon fiber filled cement mortar specimens

\begin{tabular}{|c|c|c|c|c|}
\hline \multirow[t]{2}{*}{ NO. } & \multicolumn{2}{|c|}{$\begin{array}{l}\text { Decrease rate of electrical } \\
\text { resistivity of cement mortar at } \\
3 \mathrm{~d}(\%)\end{array}$} & \multicolumn{2}{|c|}{$\begin{array}{l}\text { Decrease rate of electrical } \\
\text { resistivity of cement mortar at } \\
28 \mathrm{~d}(\%)\end{array}$} \\
\hline & $\begin{array}{l}\text { With } 3 \mathrm{~mm} \\
\text { carbon fiber }\end{array}$ & $\begin{array}{l}\text { With 6mm } \\
\text { carbon fiber }\end{array}$ & $\begin{array}{l}\text { With } 3 \mathrm{~mm} \\
\text { carbon fiber }\end{array}$ & $\begin{array}{l}\text { With } 6 \mathrm{~mm} \\
\text { carbon fiber }\end{array}$ \\
\hline 0 & 0.0 & 0.0 & 0.0 & 0.0 \\
\hline 1 & 3.9 & 17.9 & 24.1 & 43.2 \\
\hline 2 & 22.5 & 43.6 & 44.6 & 56.0 \\
\hline 3 & 48.3 & 70.2 & 68.5 & 77.9 \\
\hline 4 & 60.2 & 84.3 & 77.5 & 86.4 \\
\hline 5 & 77.3 & 87.0 & 80.9 & 92.4 \\
\hline 6 & 86.2 & 93.2 & 86.0 & 95.3 \\
\hline
\end{tabular}

With fixed water/cement ratio, the electrical resistivity of $3 \mathrm{~mm}$ and $6 \mathrm{~mm}$ carbon fiber filled cement mortar decreases as the fiber content increases. When the content is $2.0 \%$, the electrical resistivity of $3 \mathrm{~mm}$ carbon fiber filled cement mortar reaches the minimum which is $3.46 \mathrm{k} \Omega \cdot \mathrm{cm}$ at $3 \mathrm{~d}$ and $8.30 \mathrm{k} \Omega \cdot \mathrm{cm}$ at $28 \mathrm{~d}$. The electrical resistivity decreases by $86.2 \%$ at $3 \mathrm{~d}$ and $86.0 \%$ at $28 \mathrm{~d}$ compared with that of plain specimen without fiber. In 
addition, the content for minimum electrical resistivity of $6 \mathrm{~mm}$ carbon fiber filled cement mortar is also $2.0 \%$. The electrical resistivity decreases by $93.2 \%$ and $95.3 \%$, respectively. Figs. 15 and 16 indicate that the conductive property of $6 \mathrm{~mm}$ carbon fiber filled cement mortar is better than that of $3 \mathrm{~mm}$ carbon fiber filled cement mortar at $3 \mathrm{~d}$ and $28 \mathrm{~d}$ at the same fiber content.

\subsection{Microstructure of carbon fiber filled cement mortar}

The reinforcement mechanisms of carbon fiber filled cement mortar mainly include three aspects. Firstly, carbon fiber pulling out or fiber breaking (Fig.17) can enhance the mechanical properties by absorbing energy. Secondly, Fig.18 shows the hydration products adhere on the carbon fiber, which indicates that the carbon fibers well bond with the cement mortar. Thirdly, carbon fibers can restrain the growth of cracks (as shown in Fig.19 b)). All of above aspects contribute to enhancing mechanical properties.

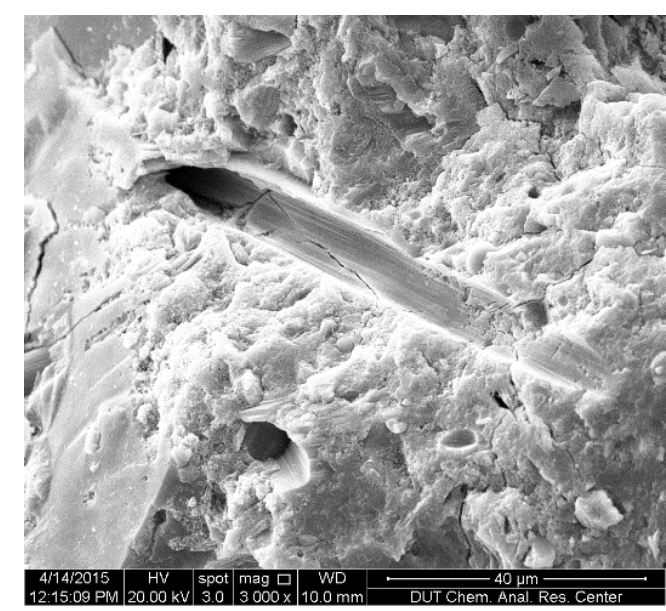

Fig.17 Microstructure of drawing mark

of specimen with $0.5 \%$ content of $3 \mathrm{~mm}$ carbon fiber

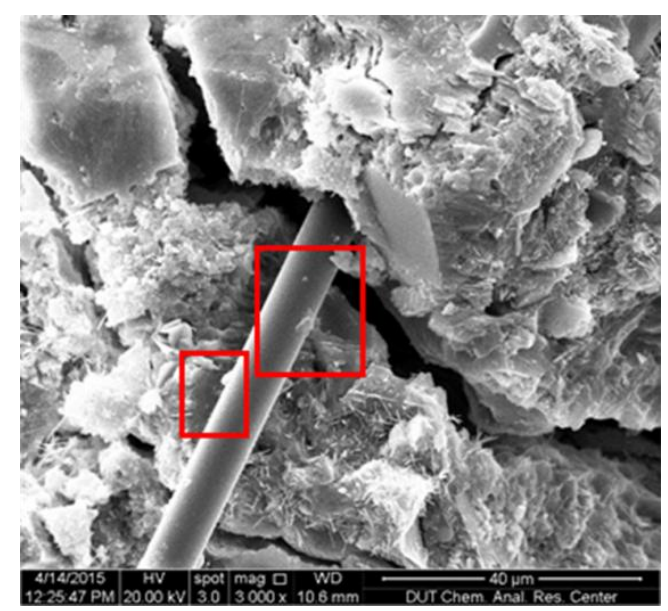

Fig.18 Microstructure of specimen with

$0.5 \%$ content of $6 \mathrm{~mm}$ carbon fiber 


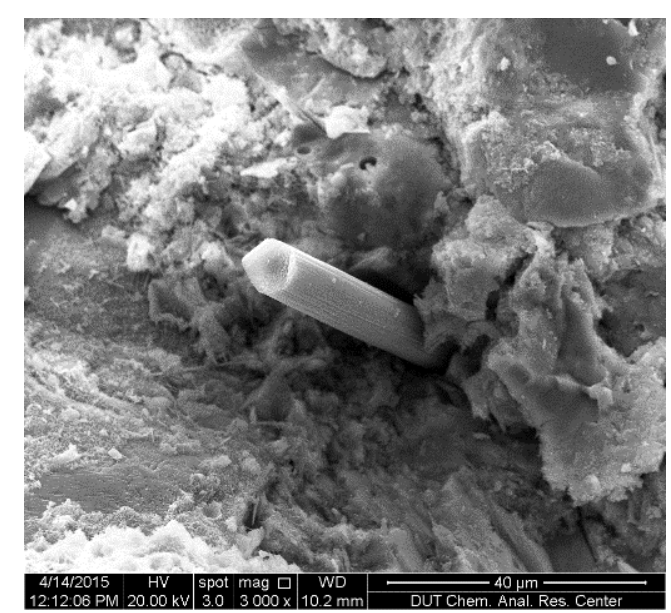

a) With $0.5 \%$ carbon fiber content

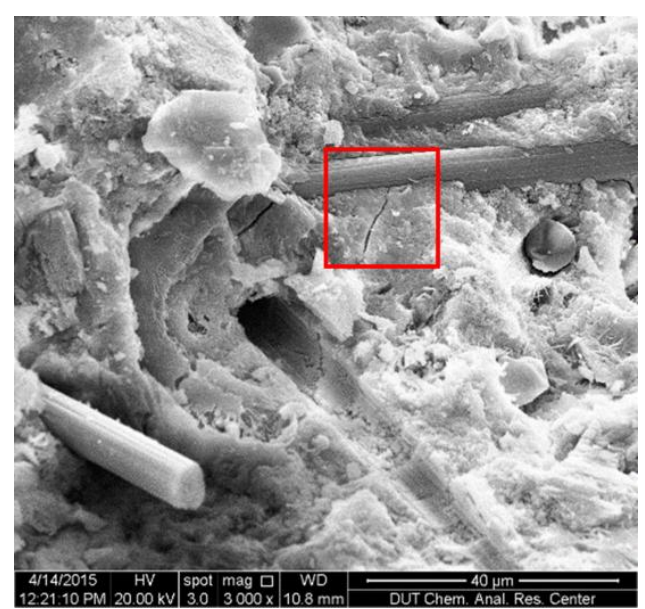

b) With $0.8 \%$ carbon fiber content

Fig.19 Microstructure of specimen containing 3mm carbon fiber

Fig. 19 shows scanning electron microscopic images of specimens with $0.5 \%$ and $0.8 \%$ of $3 \mathrm{~mm}$ carbon fiber. It can be seen that the carbon fibers distribute among the cement matrix in disorder. There are more carbon fibers in specimen with $0.8 \%$ fiber. The average center distance between two carbon fibers is shorter and the steadier conductive network can be established. Therefore, the conduction of carbon fiber filled cement mortar is enhanced with increasing of carbon fiber.

The enhancing effect of mechanical properties of carbon fiber filled cement mortar will be more obvious when the content of carbon fiber is low, while the electrical resistivity will be larger. However, the mechanical properties of carbon fiber filled cement mortar stop increasing and even decrease when the content of carbon fiber achieves a certain level. On the contrary, a stable conductive network will be formed inside the carbon fiber filled cement mortar. As a result, the electrical resistivity will reduce considerably. The contents of carbon fiber have different effects on mechanical properties and electrical property. That may be caused by that the mechanical properties are more sensitive to aggregate of carbon fibers. However, electrical conductivity 
suffers minor effect of aggregation of carbon fiber and even may be benefit from the aggregation to some degree.

\section{Theoretical calculations and analysis}

The mechanical and electrical properties of carbon fiber filled cement mortar are closely related to the volume fraction of carbon fiber, the number of carbon fiber per unit volume, average center distance between two carbon fibers and the critical pull-out length of carbon fiber in cement mortar. Based on these theoretical calculated parameters of carbon fiber in cement mortar, the behavior of carbon fiber filled cement mortar can be understand better although experimental results have also been got.

The percentage of carbon fiber volume in carbon fiber cement-based composite is called volume fraction of carbon fiber $\left(V_{f}\right)$. When the volume fraction of carbon fiber is more than a certain critical value, the mechanical and electrical properties of carbon fiber cement-based composite will be better than ordinary cement-based composite [28] .

The volume fraction of carbon fiber can be expressed as:

$$
V_{f}=V / V_{2}=m / \rho V_{2}
$$

where $V$ is total volume of carbon fiber, $\mathrm{mm}^{3}, V_{2}$ is volume of carbon fiber filled cement mortar and is $40 \times 40 \times 160\left(\mathrm{~mm}^{3}\right), \rho$ is density of carbon fiber and is $1800 \mathrm{~kg} / \mathrm{m}^{3}, m$ is mass of carbon fiber.

Then the number of carbon fiber per unit volume of carbon fiber cement-based composite $(N)$ can be determined by the formula:

$$
N=V_{f} / A_{f} L_{f}=V_{f} / \pi\left(d_{f} / 2\right)^{2} L_{f}
$$

where $A_{f}$ is cross-sectional area of carbon fiber, $\mathrm{mm}^{2}, L_{f}$ is length of carbon fiber, $\mathrm{mm}$, $d_{f}$ is diameter of carbon fiber, and is $7 \times 10^{-3} \mathrm{~mm}$.

According to Formula (2), the amount of the $3 \mathrm{~mm}$ and $6 \mathrm{~mm}$ carbon fiber per volume 
of carbon fiber filled cement mortar can be got. Fig.20 shows that the amount of $3 \mathrm{~mm}$ and $6 \mathrm{~mm}$ carbon fiber per unit volume increase as the carbon fiber content increases. The amount of $3 \mathrm{~mm}$ carbon fiber per unit volume is double that of $6 \mathrm{~mm}$ carbon fiber.

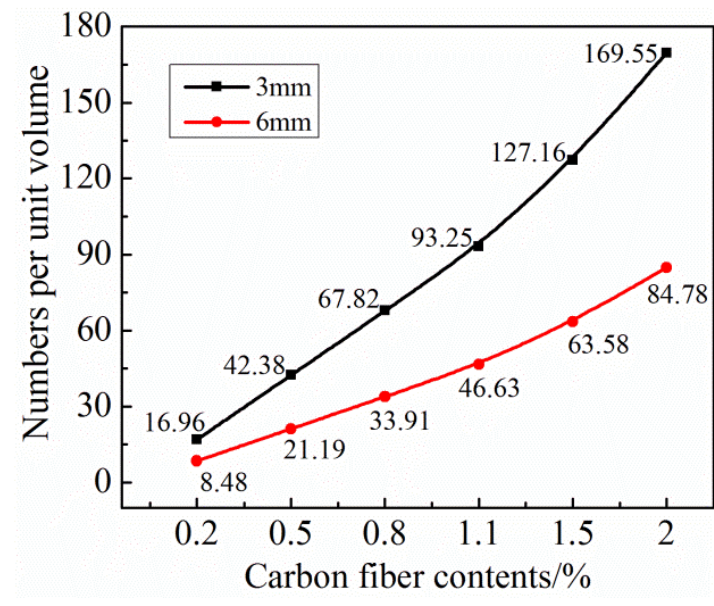

Fig.20 Carbon fiber numbers per unit volume in the carbon fiber filled cement mortar specimen

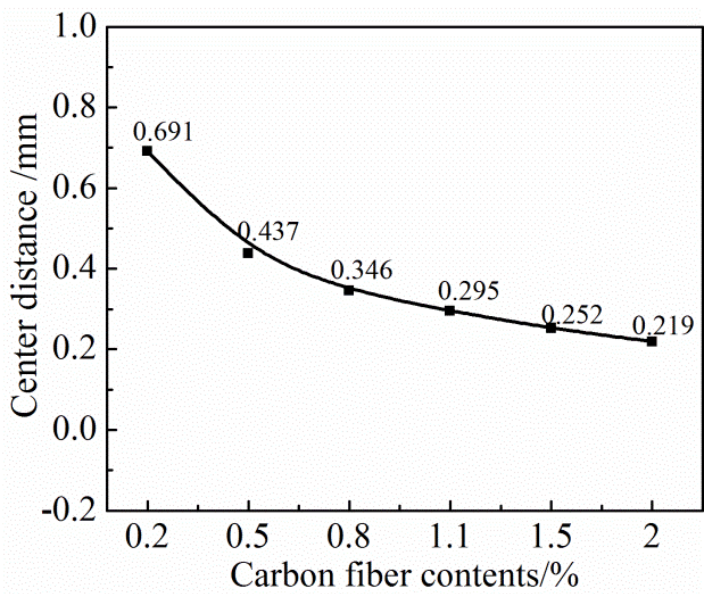

Fig.21 Average center distance between two carbon fibers in the carbon fiber filled cement mortar

Romualdi[29] built up the fiber spacing theory in 1964. He stated that the average center-to-center spacing of fibers and the cracking resistance have an inverse relationship and found that when the fibers are disorderly 3D-distributed in the cement matrix, the average center-to-center spacing $\bar{S}$ can be expressed as:

$$
\bar{S}=13.8 d_{f} \sqrt{1 / V_{f}}=0.6557 \times \sqrt{1 / m}
$$

Formula (3) indicates that the average center-to-center spacing of carbon fiber in carbon fiber filled cement mortar is only related with the diameter and mass of the carbon fiber. It does not depend on the length of carbon fiber. The average center distance between two carbon fibers in cement mortar is shown in Fig.21. 
The applied load will be transferred to the carbon fibers and carbon fibers are pulled out or snapped. The tensile strength of carbon fiber cement-based composite $\sigma_{f c}^{\mu}$ can be calculated.

$$
\sigma_{f c}^{\mu}=2 \eta_{l} \eta_{0}\left(L_{f} / d_{f}\right) \tau V_{f}
$$

where $\eta_{l}$ is coefficient of length of carbon fiber, determined by the ratio of actual length of carbon fiber and critical pull-out length of carbon fiber, $\eta_{0}$ is orientating coefficient of carbon fiber, and is 0.375 for 2D-distributed and 0.20 for 3D-distributed, $\tau$ is average bonding strength.

There is a relationship between flexural strength and tensile strength of fiber reinforced cement-based composites, as shown in formula (5) [30].

$$
\sigma_{f c}^{b}=2.44 \sigma_{f c}^{\mu}
$$

Where $\sigma_{f c}^{b}$ is the $28 \mathrm{~d}$ flexural strength of cement mortar with carbon fiber got by test and shown in Fig. 6.

Assume that the carbon fiber is snapped at half of the length, then the formula of the critical pull-out length of carbon fiber is got:

$$
L_{f}^{c r i t}=L_{f} \sqrt{\sigma_{f}^{\mu} \eta_{0} V_{f}} / \sqrt{2 \sigma_{f c}^{\mu}}
$$

where $\sigma_{f}^{\mu}$ is tensile strength of carbon fiber.

$$
L_{f}=3 m m / 6 m m, \sigma_{f}^{\mu}=3450 M P a, \eta_{0}=0.20, V_{f} \text { have been known, } \sigma_{f c}^{\mu} \text { can be }
$$
got form Eq. (5), then the critical pull-out length of carbon fiber can be got when the carbon fibers are snapped. 


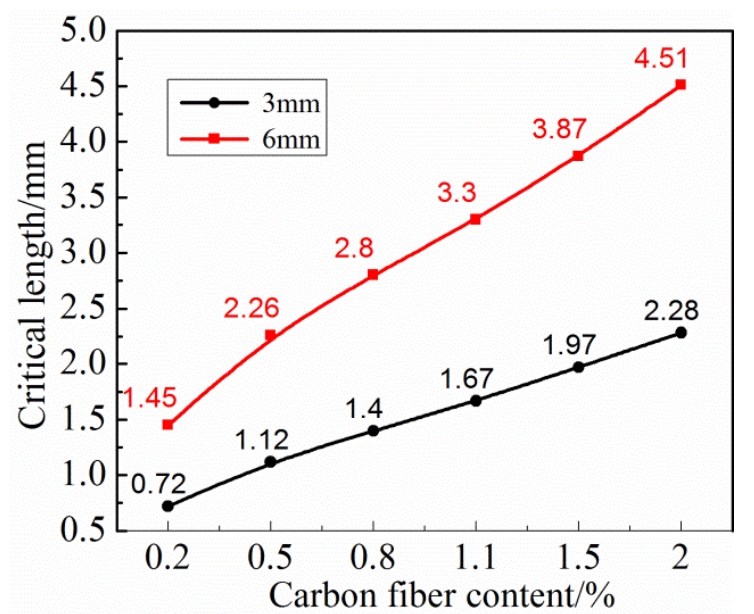

Fig.22 The critical pull-out length of carbon fibers

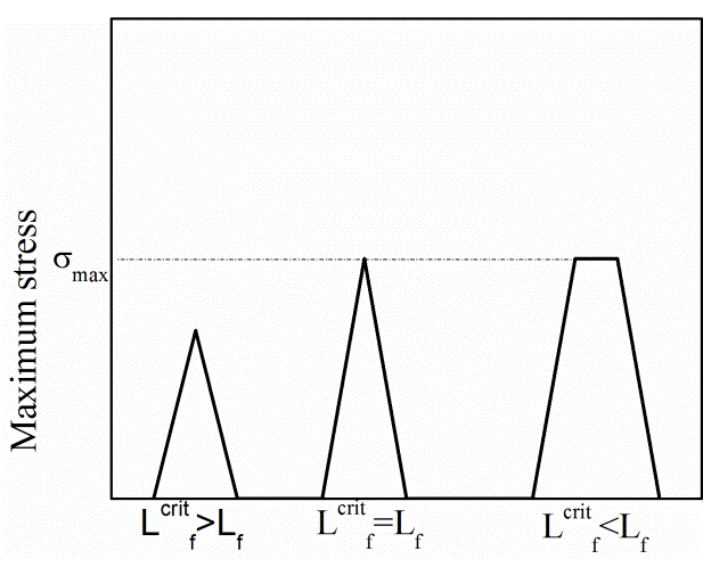

Fig.23 Relationships between carbon fiber maximum stress and critical pull-out length

Fig. 22 is the critical pull-out length of $3 \mathrm{~mm}$ and $6 \mathrm{~mm}$ carbon fibers under the loads. Fig.23 shows the relationships between carbon fiber maximum stress and critical pull-out length.

\section{Comparison of analytical and experimental results}

The impacting mechanism of carbon fibers on the mechanical properties of carbon fiber filled cement mortar shows as follows. There are microcracks distributed in the carbon fiber filled cement mortar. Under the applied load, the microcracks develop gradually and become cracks through the cement matrix. On the one hand, inside the cement mortar, carbon fibers can restrain the development of the microcracks and strengthen the mechanical behavior under the loads. On the other hand, carbon fibers owning excellent stiffness can absorb energy during the pulling-out or snapping process, which can increase the demand of failure energy of carbon fiber filled cement mortar. Figs.20 and 21 indicate that as the carbon fiber content increases, carbon fiber numbers per unit volume in the carbon fiber filled cement mortar specimens increase gradually, 
average center distance between two carbon fibers decreases gradually and the carbon fibers per unit volume can carry more load. Therefore, more carbon fibers mean better mechanical behavior of carbon fiber filled cement mortar when the carbon fiber content is low.

However, when the carbon fiber content reaches a certain value, the carbon fibers will begin clumping and bundling. It will be hard to disperse uniformly and the inner defects will increase, which cause the mechanical properties of carbon fiber filled cement mortar to decrease. In addition, even dispersion methods such as mechanical agitation and ultrasonic dispersion are applied, carbon fibers still cannot be dispersed completely. During the preparation, some air mixed in the specimens which cause air void inside the carbon fiber filled cement mortar. More carbon fibers cause larger air void. When external loads are applied, air void will be damaged firstly due to stress concentration. The mechanical properties are affected by it to some degree. Therefore, the weakening effect of air void on mechanical properties increases when the carbon fiber content increases to some extent. However, the weakening effect is still smaller than enhancing effect of carbon fibers on the carbon fiber filled cement mortar.

As shown in Fig.22, the critical pull-out length of carbon fibers increases as the carbon fiber content increases. $6 \mathrm{~mm}$ carbon fiber has larger critical pull-out length than $3 \mathrm{~mm}$ with the same content. The range of critical pull-out length of carbon fibers in the carbon fiber filled cement mortar is from $0.72 \mathrm{~mm}$ to $4.51 \mathrm{~mm}$. If $L_{f} / d_{f}>L_{f}^{\text {crit }} / d_{f}$, the carbon fiber will be snapped from the cement mortar when the carbon fiber filled cement mortar is damaged. Fig.23 shows that the carbon fibers with different critical pull-out lengths have different maximum stresses. When the carbon fiber content is less than $2 \%$, the critical pull-out length of $3 \mathrm{~mm}$ and $6 \mathrm{~mm}$ carbon fibers are both shorter 
than the actual length. $3 \mathrm{~mm}$ and $6 \mathrm{~mm}$ fibers are both snapped. They share the same maximum stress. Therefore, they have similar tensile strength when the carbon fiber content is less than or equal to $2 \%$.

The impacting mechanism of carbon fibers on electrical properties of carbon fiber filled cement mortar shows as below. The main conductive components in the carbon fiber filled cement mortar are carbon fibers and electrolyte ion. As shown in Fig.21, when the carbon fiber content is low, the average center distance between two carbon fibers is too larger for electron to transit. The main electric conduction depends on the transfer of electrolyte ion and carbon fiber. As the carbon fiber content increases, the carbon fiber numbers per unit volume in the carbon fiber filled cement mortar specimens increase gradually and the average center distance between two carbon fibers decreases gradually. In addition, few carbon fibers are in state of lapping. As a result, the main electric conduction depends on the tunnel effect of carbon fiber. As the carbon fiber content goes on increasing, stable conductive network will be established by the carbon fibers in the matrix. Additionally, some carbon fibers are lapped each other. Therefore, the main electric conduction depends on contact conduction and the electrical resistivity of carbon fiber filled cement mortar further decreased. It can be seen that the electrical resistivity decreases as the carbon fiber content increases and eventually begins to flatten. Fig.21 shows the average center distance between two carbon fibers in the carbon fiber filled cement mortar. $3 \mathrm{~mm}$ and $6 \mathrm{~mm}$ carbon fiber have the same average center-to-center spacing and it decreases as the carbon fiber content increases. When the content of carbon fibers is as low as $0.2 \%$, longer fibers have larger possibility to form bridging and establish conductive network. Therefore, $6 \mathrm{~mm}$ carbon 
fiber filled cement mortar has better electrical conductivity than that of $3 \mathrm{~mm}$ carbon fiber filled cement mortar especially at low content.

\section{Conclusions}

In this paper, different lengths and contents of carbon fibers were added into the cement mortar to fabricate high-performance and multifunctional cement-based composites, and the mechanical properties, electrical properties, microstructure and theoretical calculation of carbon fiber filled cement mortar were examined and compared with that of plain specimen without fiber. The following conclusions are drawn.

(1) The adding of carbon fibers into the cement mortar enhances the mechanical properties of cement mortar due to its ability of restraining the growth of microcracks and absorbing energy by overcoming its pull out. The obvious enhancement of carbon fiber to compressive strength of carbon fiber filled cement mortar is certainly linked with its good dispersion methods and well combination of carbon fibers and cement mortar. However, when the carbon fiber content is too high, they will clump and cause air void. The enhancement of carbon fiber to cement mortar will decrease.

(2) The electrical resistivity of $3 \mathrm{~mm}$ and $6 \mathrm{~mm}$ carbon fiber filled cement mortar reaches the minimum when the fiber content is $2.0 \%$. The main reason for the reduction of electrical resistivity is the tunnel effect and the lapping of carbon fiber. It is easy to establish the steadier conductive network for more and longer carbon fibers in the cement mortar.

(3) SEM results demonstrate that carbon fibers improve the mechanical properties of cement mortar because of absorbing energy by overcoming fibers' pulling out and 
restraining the growth of microcracks. The decreasing of average center distance between two carbon fibers contributes to enhancing the electrical properties of cement mortar.

(4) In terms of theoretical calculation, when the fiber content is over $1.1 \%$, the critical pull-out length of $3 \mathrm{~mm}$ fiber is larger than actual length and the fibers are pulled out. However, the critical pull-out length of $6 \mathrm{~mm}$ fiber is still less than actual length. As a result, the maximum stress of $6 \mathrm{~mm}$ carbon fiber is larger than that of $3 \mathrm{~mm}$ fiber, resulting in higher tensile strength and compressive strength. Meanwhile, the average center distance between two carbon fibers decreases as the fiber content increases, with no connection with length of carbon fiber. As a result, the electrical resistivity of carbon fiber filled cement mortar decreases with increasing of carbon fibers. All of above analysis match the experimental results.

\section{Acknowledgments}

The authors thank the funding supported from the National Science Foundation of China (51578110 and 51428801).

\section{References}

[1] B. Han, X. Yu, J. Ou. Self-sensing concrete in smart structures, Elsevier, Waltham, 2014.

[2] B. Han, Y. Wang, S. Dong, L. Zhang, S. Ding, X. Yu, J. Ou, Smart concretes and structures: A review, J Intel Mat Syst Str. 26 (2015) 1303-1345.

[3] M. Z. Hossain, A. S. M. A. Awal, Flexural response of hybrid carbon fiber thin cement composites, Constr Build Mater. 25 (2011) 670-677.

[4] M. Li, Y. Yang, M. Liu, X. Guo, S. Zhou, Hybrid effect of calcium carbonate 
whisker and carbon fiber on the mechanical properties and microstructure of oil well cement, Constr Build Mater. 93 (2015) 995-1002.

[5] C. Wang, K. Li, H. Li, G. Jiao, J. Lu, D. Hou, Effect of carbon fiber dispersion on the mechanical properties of carbon fiber-reinforced cement-based composites, Mater Sci Eng: A. 487 (2008) 52-57.

[6] H. A. Toutanji, T. El-Korchi, R. N. Katz, Strength and reliability of carbon-fiber-reinforced cement composites, Cem Concr Compos. 16 (1994) 15-21.

[7] J. Zhao, K. Li, H. Li, C. Wang, The influence of thermal gradient on pyrocarbon deposition in carbon/carbon composites during the CVI process, Carbon. 44 (2006) 786-791.

[8] P. Garcés, J. Fraile, E. Vilaplana-Ortego, D. Cazorla-Amorós, E. G. Alcocel, L. G. Andión, Effect of carbon fibres on the mechanical properties and corrosion levels of reinforced portland cement mortars, Cem Concr Res. 35 (2005) 324-331.

[9] J. Piekarczyk, W. Piekarczyk, S. Blazewicz, Compression strength of concrete cylinders reinforced with carbon fiber laminate, Constr Build Mater. 25 (2011) 2365-2369.

[10] Y. Ding, Z. Chen, Z. Han, Y. Zhang, F. Pacheco-Torgal, Nano-carbon black and carbon fiber as conductive materials for the diagnosing of the damage of concrete beam, Constr Build Mater. 43 (2013) 233-241.

[11]B. Chen, J. Liu, Damage in carbon fiber-reinforced concrete, monitored by both 
electrical resistance measurement and acoustic emission analysis, Constr Build Mater. 22 (2008) 2196-2201.

[12] S. Park, M. Seo, H. Shim, K. Rhee, Effect of different cross-section types on mechanical properties of carbon fibers-reinforced cement composites, Mater Sci Eng: A. 366 (2004) 348-355.

[13]Y. Xu, D.D. Chung, Carbon fiber reinforced cement improved by using silane-treated carbon fibers, Cem Concr Res. 29 (1999) 773-776.

[14]Z. Deng. Properties of carbon-steel fiber reinforced concrete under low-cyclic fatigue loading. J Hyd Eng. (2001): 39-43.

[15]M. Sun, Z. Li, Q. Mao, D. Shen, Study on the hole conduction phenomenon in carbon fiber-reinforced concrete, Cem Concr Res. 28 (1998) 549-554.

[16] J. Xu, W. Zhong, W. Yao, Modeling of conductivity in carbon fiber-reinforced cement-based composite, J Mater Sci. 45 (2010) 3538-3546.

[17]J. Xu, W. Yao, R. Wang, Nonlinear conduction in carbon fiber reinforced cement mortar, Cem Concr Compos. 33 (2011) 444-448.

[18]B. Chen, K. Wu, W. Yao, Conductivity of carbon fiber reinforced cement-based composites, Cem Concr Compos. 26 (2004) 291-297.

[19]M. Chiarello, R. Zinno, Electrical conductivity of self-monitoring CFRC, Cem Concr Compos. 27 (2005) 463-469.

[20]P. Chen, D.D. Chung, Concrete as a new strain/stress sensor, Composites Part B. 27 
(1996) 11-23.

[21]P. Chen, D.D. Chung, Carbon fiber reinforced concrete for smart structures capable of non-destructive flaw detection, Smart Mater Struct. 2 (1993) 22.

[22]X. Fu, D.D. Chung, Self-monitoring of fatigue damage in carbon fiber reinforced cement, Cem Concr Res. 26 (1996) 15-20.

[23] S. Wen, D.D. Chung, Carbon fiber-reinforced cement as a strain-sensing coating, Cem Concr Res. 31 (2001) 665-667.

[24]B. Han, J. Ou, Embedded piezoresistive cement-based stress/strain sensor, Sens Actuators A. 138 (2007) 294-298.

[25]J. Ou, B. Han, Piezoresistive cement-based strain sensors and self-sensing concrete components, J Intel Mat Syst Str. 20 (2009) 329-336.

[26]W. Wang, S. Wu, H. Dai, Fatigue behavior and life prediction of carbon fiber reinforced concrete under cyclic flexural loading, Mater Sci Eng: A. 434 (2006) 347-351.

[27]B. Han, X. Guan, J. Ou, Electrode design, measuring method and data acquisition system of carbon fiber cement paste piezoresistive sensors, Sens Actuators A. 135 (2007) 360-369.

[28]R. X. Shen, Q. Cui, Q. H. Li, New type fiber reinforced cement-based composites, China Building Material Industry Publishing House, Beijing, 2004.

[29] J. P. Romualdi, J. A. Mandel, Tensile strength of concrete affected by uniformly 
distributed and closely spaced short lengths of wire reinforcement, ACI J. Proceedings, 61 (1964), 657-672.

[30] P.J Hannant, Fibre Cements and Fibre Concretes, John Wiley \& Sons, Chichester, 1978. 